\title{
Community Concern on Environmental Conservation
}

\author{
Fajar Adie Nugraha ${ }^{1, *}$, and Maryono Maryono $^{2}$ \\ ${ }^{1}$ Master Program of Environmental Studies, School of Postgraduate Studies Diponegoro University, Semarang - Indonesia \\ ${ }^{2}$ Urban and Regional Planning Department, Faculty of Engineering Diponegoro University, Semarang - Indonesia
}

\begin{abstract}
Research on the relationship between humans and the environment is always very interesting to be studied. This paper is one of the studies of sustainable development in its implementation with the empowerment of society that comes from the community itself. So far, community studies related to development occasionally target the growth of the economic side only. Community study on the environment becomes an alternative choice, compared with human relationships with humans themselves, or humans with human needs themselves. The study of community development by looking at the environment can be a wise choice, where all activities of fulfilling human needs are always inseparable from the element of interaction with the environment. Community development that is based on the environment itself, will give a better impact, just solely. Various methods of learning human relationships. A community-based environmental assessment study can be an alternative choice to support a sustainable development mission, which is development that has a positive impact on the present and the future.
\end{abstract}

\section{Introduction}

Development, people and the environment are interrelated. Self-development is one of human effort in its main activity as the fulfillment of basic life needs. Without a development, Human can not develop, and extinction becomes an answer to that problem. The concept of the fulfillment of human needs has actually started since human civilization itself existed, the initial concept of development appears in the use of human survival methods that started from hunting and gathering, then developed into cultivation, and until now developed with various methods of fulfilling human needs. Self-development can not be separated from the environment, because why? The sustainability of a development itself is part of environment, which makes the various developments inevitably have a direct impact on the environment. Lopez and Luigi (2008) Said that The consequences of this worldview tends to be focused on exploitation of nature, resource extraction, efficiency management, and a belief that technology can solve all problems [8]. So far we have confidence, that when the development is growing rapidly, and technology is growing, so as if every environmental problem will be solved easily. However, the situation in the field finds that with the development that does not put forward the environmental assessment, no matter how sophisticated the technology used, the impact of damage to the environment tends to increase.

Hawkins (2010) points out that To be relevant in the contemporary world, social work must move beyond our traditional focus on social and economic justice. We must actively advocate for environmental justice and pursue sustainable development so that all people can live in a clean, safe, and healthy environment [6]. Our use of economic and social benchmarks to a successful development is worth reviewing. So far we tend to ignore the environmental impact directly. As a result both directly and indirectly we encounter a lot of environmental degradation occurs around the development area. Yet we as human beings, are the main perpetrators of development. So far we tend to ignore the environmental impact directly. As a result both directly and indirectly we encounter a lot of environmental degradation occurs around the development area. Yet we as human beings, are the main perpetrators of development. Denpaiboon and Amatasawatde (2012) even say that People in this generation will become an important group to run community further [3]. So that we as individual human beings can establish unity with other human individu by forming a community or society that has a role for the interests that will come.

When development has been successfully aligned with the environmental interest by us as a society. Harmony in development will be created, so the human image as a contributor to environmental damage can be

*Corresponding Author :geografifajar@gmail.com 
minimized as possible. Although the data found by Howe where the current reality, studies quantifying success of conservation and sustainable development projects are also limited. Without quantitative data on either of these aspects it is difficult to translate research into action, which is vital if conservation and sustainable development strategies are to succeed [7]. Can be used as our reference to awaken themselves to the need for study of sustainable development projects, the impact on society, environment and achievement as a means of fulfillment of basic human needs. Humans are the highest link in the environment, all natural phenomena more or less affected human activities. With that understanding we should change the paradigm as the most powerful, be the most responsible, and should be the most aware of the changes that occur in the environment. Coates (2003) even discusses the need for a new ecological paradigm in social work, which emphasizes a core theme that environmental exploitation results from the same pressures that create social injustice [2].So the real problem of development can not be separated from our social life, as well as environmental problems is actually our social problems as well.

\section{Community participation in Development}

Rapley argues that development was considered largely synonymous with industrialization. Its ultimate goal was fairly clear: to raise incomes and in the process give poor people access to the range of goods and services then widespread in developed societies [13]. It can be said that development is a means that can not be inevitable to the concept of fulfilling the needs of human life. Now as if development is a duty in a human development. Many land use changes are in the name of development. When reflecting on the existing development in the world today, no wonder impacts arise due to development, such as social and environmental issues. Social problems struck in the development process has actually been seen since the industrial revolution in Britain several centuries ago, which when the replacement of human labor into machinery resulted in the number of production of goods and services increased messages, and also the cost of production can be reduced to a minimum. The phenomenon was a remarkable development progress at that time, as if humans at that time entered into a new age of an industrial age. But behind the success of development in the field of industry, there are social problems that are quite inconvenient for the UK at that time the early symptoms of population blasting. Workers who quit their jobs automatically do not have busy in their daily lives, so they spend more time with their wives at home, and household activities contribute to increased birth rates in the UK, and indirectly increase the number of residents in the UK. The example is one form of the impact of uncontrolled development, and did not rule out, when the current development is not controlled, problems of similar problems will begin to appear to the surface.

In Reser's study he found that the condition and state of the world's natural environment is one of unprecedented fragility, escalating threats and human impacts, and massive and in many cases irreversible natural environment degradation and habitat and species loss [14].This should be a warning for us, where a lot of research related to the negative impact of uncontrolled development raises various problems. Humans unconsciously or in the realize already contribute significant changes in the environment. Myller and Spoolman also examine the topic of development, according to him, economic development is devoted to making aneconomy better by improving human well being meeting fundamental human needs for items such food, shelter, physical and economic security, and good health [12].The result of the study is actually a trigger for an advanced study, about the significant impact of a development on the environment, both quantitatively and qualitatively. The more studies on the impact of development, the more theories will be obtained as a reference in the management of a development, so that in a planning and implementation of a development can promote more complex studies, and not just economic and social.

\section{Community concern to environment}

As the subject of all the issues, humans is always in every situation called the problem. When as an individual sometimes the consequences of a problem just seem simple because it only concerns the individual, but when humans interact and form a system of society, the problems will be more complex. Society in this case is a group of people who do a development, is one of the main objects of a study of scholarship. As much as any study of a physical environmental problem, but when ignoring the study of social and human behavior, then the study just seemed to evaporate into a theory without the application. Society must be equipped with the knowledge and knowledge of environmentally conscious behavior, where when people are aware of environmental conditions, they will use that knowledge consciously in the application of their life activities, including the development context even. Babylon (2003) says there needs to be an approach to society, especially in relation to the environment, although in implementing a community-based approach to conservation it is often incompatible with established goals because too few organizations are aware of the ins and outs of the communities they are trying to mobilize. Rather than regard the communities as a small (in both population and geographic area) unified whole, more attention should be given to the processes within communities and the varying influences of different players, whether citizens or public officials [1]. The problems in the community approach are complex, the system of society, either from the simplest form of the 
neighborhood or village, to the government and the stakeholders is not as easy as it is planned. Several existing case studies show that there is a need for indepth study, about the approach to society, especially in relation to development and environmental mindset. The non-formal approach may be one of the efforts of community empowerment. Lynch (2001) finds an alternative solution to environmental approaches and environmental empowerment strategies, one of the most popular strategies that has emerged is environmental education (EE). Conservation organizations and governmental entities alike have embraced environmental education as an integral part of their agendas. Yet, there is often a lack of critical analysis regarding how EE programs are contributing to conservation goals [9]. The community must be given a real solution, and need an intensive assistance, it is necessary, because one of the best ways to instill environmental values to the community is to familiarize them in their daily activities. Without such habituation, we can be sure that various efforts of empowerment and facilitation of environmental insight will be less than the maximum.

Mallen and Corbera in his research argued that decision making around natural resource management based on traditional ecological knowledge was identified as a key factor contributing to successful conservation in both types of community-based conservation initiatives [10]. Based on the research study, it can be taken several things, among others, raises the intention of community initiative, and the provision of knowledge to the community. Both of these can be alternatives to other solutions, in addition to various methods that can be used, but to find the right formula must be tailored to the conditions where the community is located, so that the study and results in accordance with what is wanted.

\section{Environment pollution and degradation}

As a place where all the problems caused by humans are, so far as if the environment is still a priority to so many by humans. The environment is more often ignored in the name of other interests, not even rare environmental issues are seen as a stumbling block a development progress. Reser suggests environmental degradation is in large part caused by human behaviours and directly affects human health and well being [14]. It can be said that when a human ignores the environment, he is unknowingly trying to dig his own grave hole. Development should use the guidance of an environmental perspective as a basic reference in its planning, and as a human being subject to all problems, it must be used in all decision-making, especially related to development and the environment. Lynch (2001) argues in a particular case that due to the undisputed need for improved education in most tropical areas, environmental education proposals are rarely questioned or critically evaluated [9]. This is a form of abandonment of the concept of environmental education, which in fact in terms of a development and public relations environment education is an obligation in the implementation.

In its development, when development, society and environment have tried to be synchronized into one unity that can not be separated. It still needs the initiative of the community as the main actor of all policies, theories, and its application. Mallen and Corbera added that a community-based conservation initiatives, which combine traditional and official regulations as well as informal and formal sanctions established by cross-scale institutions, traditional ecological knowledge was considered the basis for sound decision making around natural resource management, alongside scientific knowledge [10]. Public awareness of environmental issues is a fundamental requirement today. As mentioned before, sometimes the local culture of society has shown the form of environmental science, but its shape is not yet packed with a more scientific concept. But it does not mean that the local culture of society is not necessarily far from the word environment rather than scientifically own scholarship. If the line drawn back, the study of the environment is already a lot, both physically environment, as well as the concept of the environment. But it should be underlined, although with all these studies the implementation and application of science is still limited and not maximized. So the study of scientific applications in the environment that is applied to the community can be a discourse of the development of human interaction studies with the environment.

\section{Sustainable Development}

The study of interaction between the environment, human and development now began to become a serious discourse and study by environmentalists. This is evident in the changing direction of world development goals that begin to lead to the sustainability of a development. Where sustainable development itself is a form of development that put forward the concept of fulfilling human needs today, but also still pay attention to the concept of needs and availability of resources for the future. DEE and QCA put forward the view that education for sustainable development, through developing pupils' skills in, and commitment to effective participation in the democratic and other decision making processes that affect the quality, structure and health of environments and society and exploring values that determine people's actions within society, the economy and the environment [4]. It should be underlined that in the implementation of sustainable development needs a commitment to active participation, in this case not necessarily charged to the stakeholders, or government, but also need to include all layers of human life order, so that in the execution of policy making, can supervise each other to the value The value of the environment in a development. When comprehensive monitoring, the implementation of sustainable development can be 
comprehensive in all lines of society, whether from individuals, to the sphere of government or related institutions. This is reasonable considering that in environmental education, there needs to be a habituation of the concept of environmental knowledge in everyday life, so that in the application of sustainable development which is the development of the concept of development and environment so also become an thing absolutely necessary. Therefore it is necessary to study more deeply about the application of environmental education in society, in relation to the achievement of sustainable development.

Dobson added that Sustainable development is at least as much about values as about techniques and technologies. For example, science might be able to tell us what the threshold tolerances of nitrogen in the atmosphere are for any given species, but it cannot tell us which species we should be concerned about. The key questions, then, are not technical - they are normative. Bearing this in mind, we have to say that we will be short-changed by any ecological citizenship curriculum that does not confront normative questions of this sort [5]. Application of such an analogy dobson proposed can indeed be a reference in determining the concept of study on environmental education, as well as how to link it to sustainable development. Because without a concept adapted to environmental conditions, or simply placing a theory on a particular study and without being based on a scientific understanding of the object of the study, the steps in decision-making or method may be less than the maximum, so the results can be far Of the unity itself. Matti, S responds that sustainable development is applied in the community, he insists that environmental citizenship must have a presence in the social, political and economic life of societies aiming at sustainable development. It is tempting to say that fiscal incentives and environmental citizenship can be pursued simultaneously, but recent research from Sweden suggests that self-interest based policy initiatives can 'crowd out' citizenly behaviour, making it less likely that such behaviour is either followed or fomented [11]. Studies of community development by looking at the environment can be a wise choice, where all activities of fulfilling human needs are always inseparable from the elements of interaction with the environment. Community development based on the environment itself, will have a better impact.

\section{Conclusions}

Human beings, and the environment, are a major component of development, the interaction between the components can lead to how development works. During this study of human interaction with the environment is still limited to the environmental impact discourse will be a human activity. Still less popularly studied to discuss the prevention because of the incompatibility of human interaction with the environment occurs again, mostly focusing on improving the consequences of the incompatibility of interaction between humans and the environment. Community studies on the environment can be an alternative choice, compared to human relationships with humans themselves, or humans with human needs themselves. The study can also support the sustainable development mission, which is development that has a positive impact on the present and the future.

\section{References}

1. Babylon, G. Ruth,The Use of Community-Based Conservation in Natural Resource Management: Case Studies from The Nature Conservancy of Virginia. Thesis. Virginia Polytechnic Institute and State University, (2003)

2. J. Coates, Ecology and social work: Toward a new paradigm. Halifax, NS: Fernwood, (2003)

3. Denpaiboon, Chaweewan and Amatasawatde Kornchakorn, Japanese Studies Journal Special Issue : Regional Cooperation for Sustainable Future in Asia. Thammasat University, (2012)

4. Department for Education and Employment (DEE) and the Qualifications and Curriculum Authority (QCA). The National Curriculum for England: Citizenship. Department for Education and Employment and the Qualifications and Curriculum Authority: London, (1999)

5. Dobson, Abdrew, Environmental Citizenship: Towards Sustainable Development.Sustainable. Development. 15, 276285. DOI: 10.1002/sd, (2007)

6. A. Hawkins, Catherin, Sustainability, Critical Social Work, Vol. 11, No.3, (2010).

7. Howe, Caroline, The Role of Education as a Tool for Environmental Conservation and Sustainable Development. Disertation. Imperial College London, (2009)

8. V. L. Lopez, andV. L. Luiggi, Participatory sustainability: Building sustainability for complexity and change. In Osborne, R. \& Kriese, P. (Eds.). Global community, global security. New York, NY: Rodopi. pp. 217-227, (2008).

9. Lynch, A. Kathryn,Environmental Education and Conservation in Southern Ecuador: Constructing an Engaged Political Ecology Approach. Disertation. University Of Florida, (2001)

10. Mallen-Ruiz, Isabel and Corbera Esteve, Ecology and Society .18(4):12, (2013)

11. Matti S. C. Berglund,Environmental Politics. 15(4): 550-571, (2006)

12. Myller, G. Tyler and Spoolman, E. Scott,Environmental Science. National Geographic Learning, (2015)

13. Rapley, Jhon. 2007. Understanding Development: Theory and Practice in the Third World THIRD EDITION.Copyright (C) 2007.

14. Reser, P. Josep, Psychology and The Natural Environment. A Position Statement Prepared for The Australian Psychological Society. The Australian Pshycology Society. Ltd, (2007) 